J. Clin. Chem. Clin. Biochem.

Vol. 28, 1990, pp. 217-219

(C) 1990 Walter de Gruyter \& Co. Berlin - New York

\title{
Direct Determination
}

\section{of Chloramphenicol Acetyltransferase (CAT) Activity in Homogenates of Transfected Mammalian Cells by High Performance Liquid Chromatography ${ }^{1}$ )}

\author{
By H. Siegert ${ }^{1}, B$. Wittig $^{2}$ and S. Wölfl ${ }^{2}$ \\ 1 Institut für organische Chemie, Sonderforschungsbereich 312, Freie Universität Berlin \\ 2 Institut für Molekularbiologie und Biochemie, Freie Universität Berlin
}

(Received December 1, 1989)

Summary: The conversion of chloramphenicol to its monoacetylated form by homogenates of pRSV CATtransfected mammalian cells was assayed by HPLC. The method differed from conventional procedures, in that the extraction of chloramphenicol and its acetylated forms into an organic solvent was replaced by treatment of the cell homogenates with acetonitrile. This allows a rapid, direct analysis by HPLC with few experimental steps.

\section{Introduction}

Since chloramphenicol acetyltransferase (EC 2.3.1.28) is not found in mammalian cells assay of its activity is used widely to monitor the transfection of mammalian cells by foreign DNA linked with the chloramphenicol acetyltransferase gene. Incubation of homogenates of such transfected cells in the presence of ${ }^{14} \mathrm{C}$-labelled chloramphenicol and acetyl CoA leads to the formation of ${ }^{14} \mathrm{C}$-labelled acetylchloramphenicol if chloramphenicol acetyltransferase is expressed. For the analysis of the reaction products, extraction with ethylacetate and subsequent thin layer chromatography were employed in the original published procedure (1). Alternatively, the extracted reaction products may be analysed by $\operatorname{HPLC}(2,3)$, which makes it possible to work with unlabelled chloramphenicol. However, extraction of cell homogenates with ethylacetate often leads to variable recoveries of reaction products. This is probably due to the small volumes involved as well as to cell type specific differences in protein/lipid concentrations.

1) This paper contains in part data from the doctoral thesis of H. Siegert.
Therefore, the recently published method of deproteinizing the suspension with acetonitrile and subsequent direct analysis of the aqueous supernatant by HPLC offers a true advantage over the established procedure.

So far the 'acetonitrile procedure' has only been used to measure chloramphenicol acetyltransferase activity in chloramphenicol-resistent bacterial strains. In adapting the procedure for the direct analysis of chloramphenicol acetyltransferase in transfected mammalian cells, one well known difference had to be taken into account. Chloramphenicol-resistent bacteria produce enough chloramphenicol acetyltransferase enzyme to convert $30 \mathrm{mmol} / \mathrm{min}$ of chloramphenicol (4). In contrast, chloramphenicol acetyltransferase expression in mammalian cells is much less effective. Under the conditions we used, only $16 \mu \mathrm{mol} / \mathrm{min}$ of chloramphenicol became acetylated. We demonstrate in this paper that nevertheless such poor chloramphenicol acetyltransferase activities can be analysed by direct loading of the HPLC with acetonitrile-treated homogenates. 


\section{Materials and Methods}

Mouse L-cells were grown non-confluently on $10 \mathrm{~cm}$ dishes in Dulbecco's modified Eagle medium containing new-born calf serum, volume fraction $0.1,37^{\circ} \mathrm{C}, 7 \% \mathrm{CO}_{2}$ incubator.

Transfection was performed by calcium phosphate precipitation and glycerol shock treatment. $500 \mu \mathrm{l}$ of $250 \mathrm{mmol} / 1 \mathrm{CaCl}_{2}$ were added cautiously to $5 \mu \mathrm{g}$ pRSV CAT DNA [1 g/l] (no mixing), underlayed with $500 \mu \mathrm{g} 2 \mathrm{X}$ Hepes buffered saline $(280 \mathrm{mmol} / \mathrm{l}$ $\mathrm{NaCl}, 50 \mathrm{mmol} / 1$ Hepes, $\left.1.5 \mathrm{mmol} / 1 \mathrm{Na}_{2} \mathrm{HPO}_{4}\right)$, and gently mixed by blowing in a few bubbles with the pipettor. The suspension was stored for $30 \mathrm{~min}$ at room temperature and the mixture added to the cell medium, followed by incubation for $4 \mathrm{~h}$. For glycerol-shock treatment the medium was replaced by $5 \mathrm{ml}$ serum-free medium containing a volume fraction 0.15 of glycerol, incubated for $2 \mathrm{~min}$, the 'glycerol medium' removed and the cells incubated for $48 \mathrm{~h}$ with normal medium.

Following incubation, the cells were washed three times with phosphate-buffered saline, harvested by scraping and resuspended in a mictrotube with $100 \mu \mathrm{l}$ of $200 \mathrm{mmol} / \mathrm{l}$ Tris $\mathrm{HCl}$ ( $\mathrm{pH}$ 7.2). L-cells were disrupted by 4 cycles of sonication (10 seconds each, with intervals of 30 seconds (Sonicator Heat Systems-Ultrasonic Inc. Model W-220F, microtip) and the debris pelleted. Simulated transfection experiments were carried out in the absence of DNA and defined amounts of purchased chloramphenicol acetyltransferase (Boehringer Mannheim $\mathrm{GmbH}$ ) were added to the disrupted cells.

Chloramphenicol acetyltransferase activity was assayed under the following conditions. The test contained $20 \mu \mathrm{l}$ of the cell supernatant ( $45 \mu \mathrm{l}$ for simulated transfection experiments) in a volume of $145 \mu \mathrm{l}(200 \mathrm{mmol} / \mathrm{l}$ Tris- $\mathrm{HCl}, \mathrm{pH} 7.2), 20 \mu \mathrm{l}$ acetylCoA (4 mmol/l), $4 \mathrm{nmol}$ chloramphenicol (SIGMA), and for simulated transfection experiments $0.001-0.032$ units of chloramphenicol acetyltransferase. After incubation (2 hours at $37^{\circ} \mathrm{C}$ ) an equal volume $(145 \mu \mathrm{l})$ of acetonitrile (Merck) was added, vortexed thoroughly, and centrifuged for $10 \mathrm{~min}$ $(9000 \mathrm{~g}) .20 \mu \mathrm{l}$ of the supernatant were injected into the HPLC. A column, $4 \mathrm{~mm}$ diameter and $120 \mathrm{~mm}$ long packed with $5 \mu \mathrm{m}$ C18 resin (Nucleosil, Macherey \& Nagel) was used for HPLC. The column was equilibrated with aqueous methanol, volume fraction 0.5, which was also used as eluent. Pressure was 195 bar, flow rate $1.5 \mathrm{ml} / \mathrm{min}$. UV absorption was measured at 275 nm (Gynko).

\section{Results and Discussion}

Figure 1 shows reference chromatograms obtained with the homogenate in the absence of chloramphenicol (fig. 1a) and with defined amounts of chloramphenicol and chloramphenicol diacetate added (fig. 1b). UV-absorbing cellular material and buffer ingredients (Tris) elute between $0.3 \mathrm{~min}$ and $1.3 \mathrm{~min}$. Chloramphenicol has a retention time of $1.9 \mathrm{~min}$, its diacetylated form $4.4 \mathrm{~min}$. A small peak eluting at $2.9 \mathrm{~min}$ is probably due to small amounts of monoacetylated chloramphenicol in the chloramphenicol diacetate stock. Even if a cell line should contribute more UVabsorbing material it will not interfere with the relevant peak of chloramphenicol monoacetate.

Figure 2 shows the results of simulated transfection experiments where increasing amounts of commercially available chloramphenicol acetyltransferase

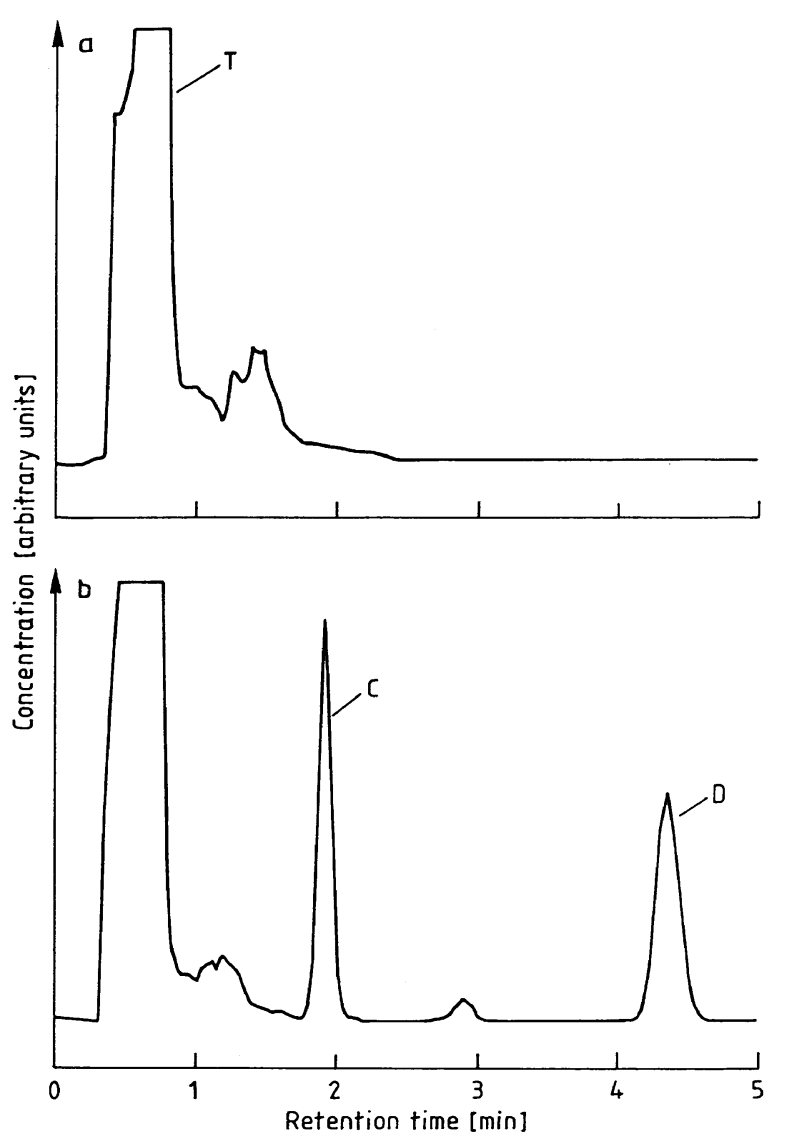

Fig. 1. Reference chromatogram

a. Cell homogenate in the absence of chloramphenicol and chloramphenicol diacetate. ' $T$ ' denotes peak due to Tris buffer.

b. $4 \mu \mathrm{mol}$ of chloramphenicol and chloramphenicol diacetate added to homogenate (same as in a.). $C$ ' and ' $D$ ' denote peaks due to chloramphenicol and chloramphenicol diacetate, respectively.

were added. Consequently, the peak of chloramphenicol decreases in correspondence to the increase of chloramphenicol monoacetete. Again the retention times of chloramphenicol peaks are not affected by any interference from cell homogenates.

The acetylation reaction of chloramphenicol is linear for 0.004 units of chloramphenicol acetyltransferase and $4 \mathrm{nmol}$ of chloramphenicol. For higher amounts of chloramphenicol acetyltransferase, linearity can be obtained with higher concentrations of substrate (data not shown). The reactants are used in concentrations appropriate to the chloramphenicol acetyltransferase activity expected in transfected mammalian cells.

As expected from the results shown in figures 1 and 2 the small amount of chloramphenicol acetyltransferase activity present in transfected cells can indeed be analysed by direct loading of the HPLC (fig. 3). 


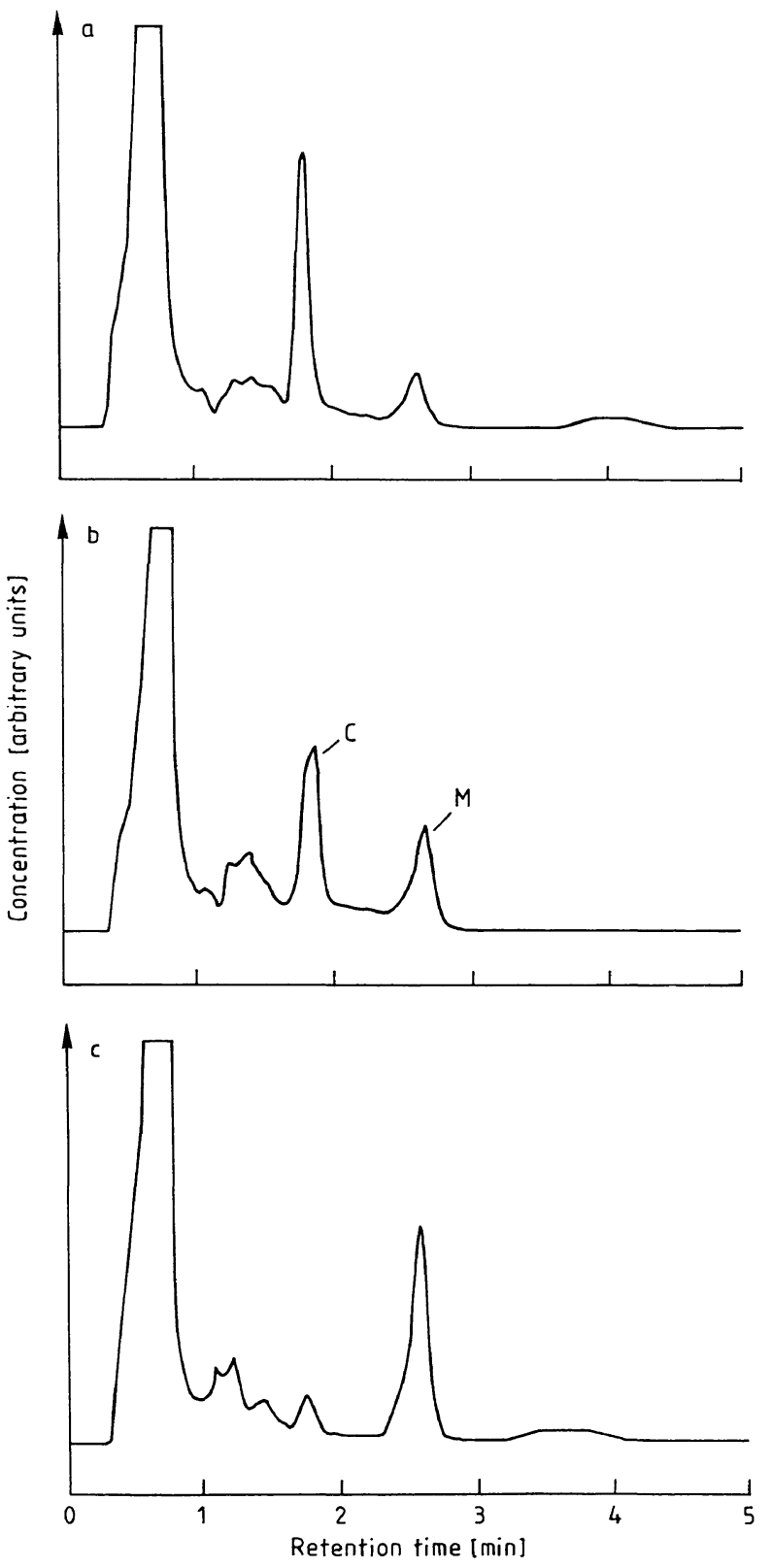

Fig. 2. Assay for chloramphenicol acetyltransferase activity in simulated transfection experiments.

Increasing amounts of chloramphenicol acetyltransferase were added to cell homogenates.

a. 0.002 units

b. 0.004 units

c. 0.016 units.

$C$ ' and ' $M$ ' denote peaks due to chloramphenicol and chloramphenicol monoacetate, respectively.

\section{References}

1. Gorman, C. (1985) High Efficiency Gene Transfer into Mammalian Cells, Chapter 6. In: DNA cloning, Volume II, A practical approach, p. 156, IRL Press.

2. Burzio, L. O., Brito, M., Zarraga, A. M. \& Siddiqui, M. A. Q. (1988) Assay of chloramphenicol acetyltransferase by high-performance liquid chromatography. Gene Analysis Techniques 5, 5-8.

3. Young, S. L., Jackson, A. E., Puett, D. \& Melner, M. H. (1985) Detection of Chloramphenicol Acetyl Transferase Activity in Transfected Cells: A Rapid and Sensitive HPLCBased Method. DNA 4, 469-476.

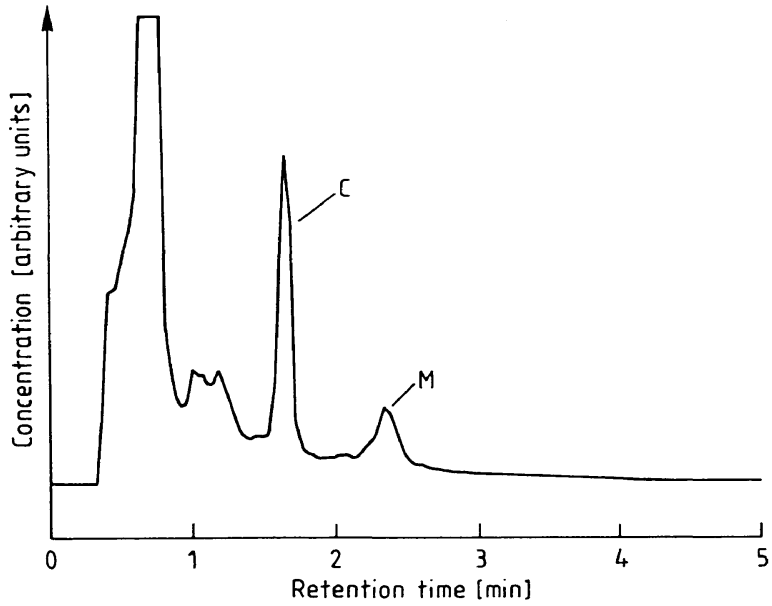

Fig. 3. Assay for chloramphenicol acetyltransferase activity in transfected mammalian cells.

' $C$ ' and ' $M$ ' denote peaks due to chloramphenicol and chloramphenicol monoacetate, respectively.

Cells were transfected with the plasmid pRSV CAT carrying the bacterial chloramphenicol acetyltransferase gene under the control of a promotor of Rous sarcoma virus. Only one fifth of the homogenate from $\sim 10^{6}$ cells was employed to produce the monoacetylated form of chloramphenicol. Thus, even the amounts of cells used with the conventional chloramphenicol acetyltransferase assay procedures yield sufficient peak sizes. In summary our procedure allows for quantitative as well as qualitative measurement of chloramphenicol acetyltransferase activity in transfected cells with a minimum of experimental steps involved. Results may be obtained within 3 hours. This is a fraction of the time needed for the radioactive chloramphenicol acetyltransferase assay.

\section{Acknowledgement}

This work was supported by Bundesministerium für Forschung und Technologie, by 'medac' (Project Transfektion...) and by "Trude Goerke Stiftung für Krebsforschung". We thank Dr. $G$. Rossi and Prof. J.-H. Fuhrhop for helpful advice, W. Lamer and $C$. Zimmermann of the Institut for Organische Chemie for help with HPLC methods and discussion of results.

4. Lovering, A. M., White, L. O. \& Reeves, D. S. (1986) The assay of chloramphenicol acetyltransferase activity by high performance liquid chromatography. Antimicrob. Chemother. $17,821-826$.

Horst Siegert

Institut für Molekularbiologie und Biochemie Arnimallee 22

D-1000 Berlin 33 
